\title{
Igualdad y diferencia en la profesionalización de las artistas. Comentarios a los textos de Alejandra Val Cubero y Natalia Izquierdo
}

\author{
Constanza Tobío \\ Universidad Carlos III de Madrid. Departamento de Ciencia Política y Sociología \\ ctobio@polsoc.uc3m.es
}

\section{Resumen}

A partir de los conceptos de igualdad y diferencia, se discuten las formas de profesionalización de cuatro mujeres artistas españolas. Solo en el caso de Maruja Mallo se observa una trayectoria equiparable a la de los hombres artistas, tanto en lo que se refiere a la formación académica en las escuelas de bellas artes, como al reconocimiento por parte de la crítica especializada, a la autonomía económica que le confiere su actividad como pintora y a la separación de su vida personal y amorosa respecto de su trabajo profesional. En los otros tres casos, los de la pintora Amalia Avia y las escritoras Carmen Martín Gaite y Carmen Laforet, hay una tensión entre la vida artística y la vida personal, en especial en lo que se refiere a la relación con los hombres, que se resuelve en supeditación, evasión o conflicto.

Palabras clave: mujeres; profesiones liberales; pintura; literatura; estudios de las mujeres.

\section{Abstract. Equality and difference in the professionalization of women artists: Comments on the Texts of Alejandra Val Cubero and Natalia Izquierdo}

The paths to professionalization of four Spanish women artists are discussed from an equality-difference perspective. Maruja Mallo is the only woman with a trajectory comparable to that of male artists in terms of formal fine arts training, recognition by specialized critics, economic independence through painting, and the separation between her personal and sentimental life and professional activity. In the case of the painter Amalia Avia and the writers Carmen Martín Gaite and Carmen Laforet, there existed a tension between their lives as artists and their personal lives, particularly regarding men, which was resolved through dependence, evasion or conflict.

Keywords: women; liberal professions; painting; literature; women's studies. 


\begin{aligned} & \multicolumn{2}{c}{ Sumario } \\ & Vocación, formación y reconocimiento Antes y después de la Guerra Civil \\ & Los hombres Conclusión \\ & Las amigas artistas Referencias bibliográficas \end{aligned}

Alejandra Val Cubero y Natalia Izquierdo nos presentan cuatro historias, hermosamente contadas, de mujeres maravillosas con vidas difíciles y una obra artística destacable. Ser artista entraña, sin lugar a dudas, una identidad compleja, pero en el caso de los hombres el hecho de serlo no añade complejidad, a diferencia de lo que ocurre con las mujeres. En este caso, ser artista es superar el ser mujer: son artistas a pesar de ser mujeres. Y ese sobreponerse al propio género puede interpretarse en clave de igualdad o diferencia, seguramente el gran debate del feminismo.

La lucha por la igualdad tiene, para las mujeres, el peligro de minimizar u obviar los poderosos obstáculos que la impiden, con lo cual se reproduce la desigualdad. Por el contrario, el énfasis en la diferencia tiende a naturalizarla, como si fuera inherente al género femenino, y se reproduce, también así, la desigualdad con los hombres. Tal como ha puesto de relieve Carole Pateman (1989), el dilema de Wollstonecraft, así denominado en homenaje a la pensadora feminista pionera ${ }^{1}$, no tiene solución en el marco de la dominación patriarcal. Las mujeres están condenadas a desenvolverse entre la reivindicación de hacer lo que pueden hacer los hombres y la de aquello que hacen como mujeres. De una u otra manera, vuelven a la subordinación y, sin embargo, en el camino, avanzan.

De manera similar a lo que ocurre con el resto de las mujeres, también las artistas eligen —o se sitúan sin haberlo decidido- en la igualdad o la diferencia. Maruja Mallo representa bien una trayectoria de asimilación a los comportamientos masculinos, que hubiera podido ser la de un hombre. Adquiere una formación artística académica, lo cual no le impide familiarizarse también con las corrientes pictóricas de vanguardia, de las que acabará formando parte. Desde muy pronto, participa en exposiciones en las que presenta su obra, bien acogida por la crítica, y se gana un creciente reconocimiento como pintora. Ser artista constituye su identidad y el arte es su forma de ganarse la vida.

Carmen Laforet representa un caso opuesto. Su vida es el desgarro entre ser mujer y ser artista. Fracasó como madre —o así lo percibía-, a pesar de haber tenido cinco hijos, y fracasó como escritora, ya que no escribía lo que quería, al final no sabía lo que quería escribir y, en los últimos años de su vida, ni siquiera podía escribir. Sin embargo, escribió un libro mítico y perdurable. Carmen Laforet quería encontrar una forma de ser escritora siendo mujer,

1. Mary Wollstonecraft, pensadora feminista del siglo XVIII que reivindicó los derechos de las mujeres en los años de la Revolución Francesa (1977). 
una forma diferente, femenina, de ser artista e incuso habla de un «feminismo femenino" como utopía superadora de las tensiones a las que se enfrentan las mujeres en la construcción de su identidad. Quizá eso sea lo que sí encuentra, sin haberlo buscado ni esperado, Amalia Avia, artista y esposa de artista, artista y madre de artista. Pero su condición de pintora está en un segundo plano respecto de su marido, Lucio Muñoz, y probablemente respecto de sus propias prioridades. El reconocimiento de su obra es muy tardío, solo llegará al final de su vida e incluso después. Carmen Martín Gaite también fue esposa de artista, del escritor Rafael Sánchez Ferlosio, además de madre. Aunque desarrolló una carrera académica y literaria, toda su vida tiene algo huidizo, difícil de aprehender. Hay algo opaco y misterioso en su forma de vivir y de ser, de lo que su autobiografía El cuarto de atrás solo da algunas claves. La regresión a un mundo propio parece haber sido una de sus estrategias de supervivencia en un entorno que se adivina hostil a su vocación.

\section{Vocación, formación y reconocimiento}

Alejandra Val Cubero señala varias condiciones que debe reunir el artista profesional: la vocación, la competencia especializada y el reconocimiento social, que, supuestamente, se consiguen tras el paso por la academia, en el caso de la pintura. Todo ello es problemático para las mujeres. Su vocación, es decir, la capacidad para crear, ha sido, implícita o explícitamente, puesta en duda, aunque ha encontrado, ya desde el siglo XIX, defensores como Stuart Mill, quien, probablemente inspirado por su mujer, la feminista Harriet Taylor, afirmó que la supuesta falta de creatividad femenina no es más que el resultado de sus carencias en materia de educación (Stuart Mill y Taylor Mill, 2001). Manuel Cerezales, el marido de Carmen Laforet, comparte esas dudas acerca de su mujer y se refiere de distintas maneras a su falta de capacidad creadora, por no inventar sino escribir siempre sobre algo ocurrido o vivido (Izquierdo López, 2013), tendencia que procurará infructuosamente modificar. Late, sin embargo, la sospecha de que el rechazo al realismo literario fuera el temor a verse él mismo retratado o a una comparación que no le fuera favorable.

Tampoco el acceso a la formación es un camino fácil para las mujeres. En el pasado, la prohibición era con frecuencia explícita, como denuncia Virginia Woolf (2008) cuando se le prohíbe entrar en la biblioteca de Oxbridge, aunque más frecuentemente era una opción descartada, en especial, cuando se trataba de enseñanzas muy especializadas, como las artísticas. Maruja Mallo es la excepción en este sentido. Su vocación y su capacidad se reconocieron muy pronto. Superó brillantemente los exámenes de acceso a la Real Academia de Bellas Artes de San Fernando con los elogios de los profesores, aunque, a la vez que felicitan a la candidata, hacen notar que fue la "única señorita aprobada» (Val Cubero, 2013). Las dotes excepcionales de Maruja Mallo se ponen de manifiesto en su expediente académico, que revela, en la mayor parte de las materias, las máximas calificaciones (Nuevo Cal e Ínsua López, 2011: 41-42). Ninguna de las otras artistas estudiadas tuvo una educación formal en el campo 
del arte. Carmen Martín Gaite estudió en la universidad y terminó la carrera, pero ello tenía más que ver con una actividad aceptable socialmente para una joven de clase media provinciana y conservadora que con un proyecto vital como escritora. Para Carmen Laforet y Amalia Avia la dedicación artística tuvo algo de sobrevenido e inesperado.

La cuestión del reconocimiento de la obra artística plantea, en primer lugar, preguntas acerca de cómo se constituye el «campo» artístico, en el sentido que Bourdieu $(1988,1991)$ da al concepto, además de quién y cómo reconoce qué y por qué. Por otra parte, el reconocimiento puede entenderse en oposición a la redistribución, como la otra cara de la desigualdad de clase, de género o de otro tipo, tal como plantea Fraser (Fraser y Honneth, 2006). El reconocimiento se asocia, así, al estatus weberiano, frente a la dimensión del acceso a los recursos materiales.

Maruja Mallo consigue un temprano reconocimiento de la crítica especializada y de la intelectualidad de la época, entre las cuales destaca la muy favorable de Ortega y Gasset, así como la de Gómez de la Serna y de Giménez Caballero. También hubo personajes destacados, como Juan Ramón Jiménez o Luis Buñuel (Nuevo Cal e Ínsua López, 2011: 155), que emitieron juicios muy negativos sobre su pintura, pero, en todo caso, nunca generó indiferencia, sino que, de ella y de su pintura, se hablaba y se escribía, y lo hacían los grandes personajes de la vida pública.

Para Carmen Laforet, el reconocimiento fue muy temprano e imprevisto y tuvo insospechadas consecuencias sobre su trayectoria posterior. Gana el Premio Nadal con solo veinticuatro años y su novela Nada se convierte en un gran éxito editorial, ante el que la sociedad española no permanece indiferente. Muestra el mundo mediocre y mezquino de los vencedores del franquismo, un retrato sutil que no pueden dejar de mirar, aunque tampoco, quizá, de vengarse después. El libro le costó a Carmen Laforet la ruptura con su familia de Barcelona, con la que había vivido un año y cuyo mundo reflejó, así como el temor de su padre y de su futuro marido a verse ellos también retratados en sus libros posteriores. Ninguno, sin embargo, es comparable a Nada, quizá porque ya no pudo permitirse escribir con la libertad de la que disfrutó con el primero.

Si la trayectoria de Maruja Mallo muestra un camino de búsqueda del reconocimiento a través de los medios habituales en el mundo de la pintura y la de Carmen Laforet, su encuentro inesperado, en los otros dos casos estudiados no hay ni una cosa ni otra, sino más bien una cierta modestia que se corresponde con su logro tardío y más limitado.

Mallo es la única de estas cuatro artistas cuya actividad está plenamente profesionalizada, según los cauces establecidos y por los que discurre habitualmente la carrera artística de los hombres. Tiene a su alcance, en cada momento, los medios necesarios para pintar y acceso a espacios de difusión de su obra. Para las otras tres artistas, el propio acceso a los medios que requiere su trabajo es problemático. Carmen Laforet, por ejemplo, recuerda la temporada que pasó en Madrid, en casa de una tía suya que, a pesar de vivir en un piso pequeño, le dejó una habitación para ella sola con una mesa para escribir, el único lugar en 
el que lo pudo hacer sin angustia. También Amalia Avia descubre la importancia de un lugar para la creación, la habitación propia de Virginia Wolf, cuando comparte con otras pintoras un estudio en Madrid. Y quizá «el cuarto de atrás» de Carmen Martín Gaite, rememoración del único espacio de libertad en su infancia, sea una habitación propia interior que la acompañará toda la vida.

Hay, sin embargo, otros factores que, en el caso de estas cuatro artistas, intervienen, a veces de forma decisiva, en su quehacer artístico. En primer lugar, la relación con los hombres, tanto maridos y parejas como padres. En segundo lugar, las amigas que aportan una red de ayuda y complicidad a mujeres pioneras en muchos momentos invadidas por el desasosiego o la inseguridad. Otro factor determinante es el momento histórico que les toca vivir: la República, la guerra y la posguerra. En unos pocos años, la sociedad española avanza primero y retrocede después, lo cual incide fuertemente, aunque de distintas maneras, en las cuatro vidas estudiadas.

\section{Los hombres}

Maruja Mallo no se casó nunca, ni tampoco tuvo hijos. Entabla con los hombres relaciones, sin duda, muy distintas de lo que era habitual en su época. Relaciones que se pueden calificar de igualdad. Tuvo con Rafael Alberti una larga historia de amor y compañerismo. Hay una influencia mutua en la obra de los dos artistas durante ese periodo y una declarada admiración del poeta hacia la pintora (Nuevo Cal e Ínsua López, 2011: 59). Entre los amigos de la residencia de estudiantes, Mallo es una más, así como en las tertulias del Madrid de los años treinta, generalmente masculinas, y más aún en París, donde va becada por la Junta de Ampliación de Estudios y se relaciona con pintores como Picasso, Bretón, Aragón o Magritte.

Hay, sin embargo, un hombre que ejerció una influencia fundamental en la trayectoria artística de Maruja Mallo, su padre, sin cuyo decidido y temprano apoyo a su formación como pintora seguramente no habría alcanzado la sólida base que adquirió en la escuela de arte de Avilés y en la Academia de Bellas Artes de San Fernando. Ello le permitió, además, acceder a una plaza de profesora de dibujo mediante oposición, lo cual marca claramente la voluntad de hacer de su arte una actividad profesional.

Las otras tres artistas estudiadas se casaron y tuvieron hijos, aunque solo en el caso de Amalia Avia fue un matrimonio feliz y duradero. Su marido era un pintor consagrado con quien compartió el mundo artístico de la vanguardia española de la posguerra, aunque ella seguiría su propio camino realista, menos valorado en su medio. En la autobiografía que escribió, hace un retrato lúcido de la subordinación de las mujeres pintoras de su tiempo, a las que llega a calificar de "segundonas», frente a los hombres, los auténticos protagonistas. Y así fue también en su vida, a pesar de la complicidad con su marido.

Los matrimonios de Carmen Martín Gaite y Carmen Laforet, en cambio, fueron mucho más complicados y acabaron en divorcio. De Martín Gaite, no se sabe mucho, en realidad, a pesar de que escribiera una novela autobiográfica. 
Tampoco el que fue su marido, Rafael Sánchez Ferlosio, ha escrito o hablado de su vida en común, aunque todavía podría hacerlo. Pero quizá se pueda leer entre líneas en algunos de los escritos de Martín Gaite, en especial de la permanente idea de fuga, de refugio o fantasía frente a una realidad seguramente distinta de la que desearía. La fuga o huída fue también una idea recurrente en Carmen Laforet, quien se definía como «vagabunda». De ella y de las relaciones con su padre y con su marido, sabemos mucho más. Ambos temieron y exigieron no verse convertidos en personajes de sus novelas, lo cual sin duda plantea interrogantes acerca de su relación con la escritora. Manuel Cerezales intentó incluso que desparecieran las cartas intercambiadas con su mujer. No son, sin embargo, casos únicos. Por ejemplo: Manuel Murguía, el marido de Rosalía de Castro, quemó su correspondencia y desaparecieron prácticamente todas sus cartas, sin que falten sospechas acerca de sus auténticos motivos.

Cerezales de alguna manera descubrió a Laforet como escritora, descubrió que tenía algo especial, seguramente único. De hecho, fue quien la animó a presentarse al Premio Nadal y la orientó en el mundo literario. En los primeros momentos de su relación, él la admira y la promueve. Parece ser lo que ella busca, alguien —un hombre- que la guíe, y deposita en él una confianza plena. Al poco tiempo de su matrimonio, la percepción cambia. Carmen Laforet llega a escribir que tenía miedo de que su éxito literario despertara los celos de su marido, al fin y al cabo, también escritor. Él la guía, tal como ella deseaba, pero su intento de hacerle cambiar la forma de escribir acaba produciendo en Laforet una inhibición, una dificultad creciente para escribir de la que no se recuperará, ni siquiera cuando se divorcia de él. De forma recurrente, buscará la huída en diferentes formas, del misticismo al desapego de la cotidianidad o la fantasía, y cuando efectivamente huye, está demasiado desgarrada como para poder encontrarse.

La relación de las artistas con sus maridos o, dicho de otra manera, de los hombres con mujeres artistas no parece ser fácil. Con frecuencia, ellos frustran, directa o indirectamente, su capacidad artística individual, tal como ocurrió en el caso de Carmen Laforet. Pero hay casos todavía más extremos, como la prohibición de ejercer su profesión después de casarse, casi la norma general hasta no hace tanto tiempo. Puede, por ejemplo, recordarse como Gustav Mahler prohibió a su mujer Alma, compositora como él, que siguiera trabajando, y solo al final de su vida accedió a que publicara algunas canciones (VVAA, 2008). Frecuentemente, del talento femenino se beneficiaba el hombre a través de su ayuda anónima, como ocurrió con Zenobia Camprubí y Juan Ramón Jiménez o, ya en forma de plagio, con Martínez Sierra y María Lejárraga, quien había en realidad escrito algunas de las obras de teatro que él publicó con su nombre. Hay que decir, sin embargo, en cierto descargo de estos hombres, que esa apropiación de las capacidades de sus mujeres se produce en el marco de un modelo familiar en el que el hombre representa al conjunto de sus miembros y el grado de individualización es menor que el de hoy. Pero pocas veces encontramos lo contrario, el marido que, consciente de la capacidad de su mujer artista, dedica su vida a estimularla y desarrollarla. Fue, por ejemplo, el 
papel que asumió Leonard Woolf con Virginia (Quentin Bell, 1972) o que se encuentra con más frecuencia en otros ámbitos artísticos, donde la presencia de las mujeres es mayor, como en la ópera. Ello implica la aceptación de una posición secundaria en la que, a los hombres, no les resulta fácil desenvolverse.

En resumen, el papel de los hombres en las vidas de estas artistas no puede ser más dispar. Para Maruja Mallo, los hombres parecen haber sido una influencia benefactora, desde su padre hasta Alberti y los muchos que reconocieron su valía, los cuales la ayudaron en su consolidación artística. Pero ella no parece haber pedido o esperado algo diferente de lo que pediría un hombre. No delegaba el timón de su vida, sino que lo empuñó con determinación. Y nunca tuvo un marido.

Amalia Avia podría representar una armónica relación de complementariedad con Lucio Muñoz. Con él, descubre y comparte una vocación afín, aunque, cuando hace balance de su vida y de las mujeres de su entorno, se da cuenta de que hay regularidades en clave de género que relegan a las artistas a un lugar secundario. Carmen Laforet, en cambio, tiene que llevar la pesada carga del éxito inesperado sin ser consciente de que a las mujeres no se les perdona fácilmente.

\section{Las amigas artistas}

Trabajar en el arte, más allá de un adorno cultural femenino, supone para las mujeres oponerse a la socialización de género, ser distintas. Por ello, probablemente, el apoyo y la ayuda mutua entre las artistas tienen una importancia especial para las pioneras. La mera existencia de otras pintoras o escritoras, sin duda, fortalece la dedicación profesional al arte como camino posible también para las mujeres. En todos los relatos de vida, aparecen compañeras o amigas como relaciones muy especiales. Maruja Mallo, por ejemplo, compartía con Concha Méndez transgresiones como el ir por la calle sin sombrero o a tertulias masculinas (Nuevo Cal e Ínsua López, 2011: 55-57). Amalia Avia recuerda a las pintoras con las que trabajaba en el mismo estudio y se atrevía a hacer cosas que, en los años cuarenta, no se consideraban apropiadas para las mujeres, como pintar desnudos o beber vino.

A través de las amigas, también se descubrían otros mundos; durante los años de la República, en círculos de debate como el Lyceum Club Femenino y otras asociaciones culturales de mujeres. Después de la guerra, todo se vuelve clandestino, pero será una hija de maestros represaliados, amiga de la infancia de Carmen Martín Gaite, quien le desvele la otra cara de la realidad del franquismo. Hay también amigas literarias que, en un envoltorio rosa, parecen lanzar algunos mensajes de emancipación o al menos de independencia, como Elena Fortún o Elisabeth Mulder.

Quien más cultivó la relación con las amigas fue Carmen Laforet, y de ello se conservan variados testimonios y documentos. Frente a la difícil relación con los hombres, en las amigas encontró comprensión y ayuda, tanto para las cuestiones prácticas de la vida, como para sobreponerse a su recurrente 
inseguridad. Entre esas amistades, corresponde un papel especial a la tenista e intelectual Lilí Álvarez, quien acabó en un feminismo sui generis ${ }^{2}$, una relación que, en otro contexto social e histórico, podría, quizá, haber liberado su yo íntimo y su voz como escritora.

\section{Antes y después de la Guerra Civil}

Por razones de edad, Maruja Mallo fue la única de las cuatro artistas que vivió plenamente los años de la República, más aún, por su propio carácter que, seguramente, le permitió disfrutar al máximo la libertad y la apertura de aquella hermosa época. Vivió lo que después, en los años cuarenta y cincuenta, era impensable en la Nueva España de la Sección Femenina y mantuvo siempre una libertad de costumbres, hasta en la propia forma de vestir, que, cuando vuelve a España, en los años sesenta, sigue siendo transgresora. El exilio le ahorró los peores años de la posguerra.

Laforet, Martín Gaite y Avia, en cambio, sufren el retraso cultural de la España franquista como artistas, y probablemente también como personas. Las dos primeras tienen rasgos en común en las ideas de fuga o de huída, siempre frustradas, en ambas escritoras. Analizan extensamente ese aspecto de su personalidad que les impide ir más allá de las barreras que su medio social les impone. Son conscientes del deseo de huída y lo expresan de mil maneras, pero no encuentran una salida. El temor o el desconcierto fueron más fuertes. Cabe preguntarse qué hubieran pensado de Maruja Mallo de haberla conocido en aquellos años. ¿Hubiera sido un referente o, por el contrario, la hubieran visto como una «loca»?

Para Amalia Avia, proveniente de la España provinciana de clase media, Lucio Muñoz representó la modernidad y la vanguardia. A través de él, se integra en el mundo artístico más avanzado y cosmopolita, dentro de lo que permitía la dictadura. Lo que no está claro es si pertenece a ese mundo como artista de pleno derecho o más bien como consorte. En todo caso, encontró un medio en el que poder desarrollar su actividad como pintora y enriquecerse del contacto con los creadores más abiertos e interesantes que había en la España de aquellos años.

\section{Conclusión}

La investigación de Natalia Izquierdo y Alejandra Val Cubero indaga en la profesionalización de cuatro mujeres artistas, un punto de vista que apunta a las particularidades, a los obstáculos o a las formas como se produce, en comparación con el modelo masculino de ejercicio del arte como actividad laboral. Este es el punto que permite diferenciar el caso de Maruja Mallo de los otros tres. La pintora aprende a pintar para trabajar, primero como profesora y

2. Lilí Álvarez escribió la introducción a la primera edición en español del libro de Betty FRIEDAN (1974), La mistica de la feminidad, de quien se declara gran admiradora. 
después como artista liberal. Una trayectoria igual a la que, sin duda, siguieron sus otros compañeros de la Escuela de Bellas Artes, entre ellos Salvador Dalí. Se podría decir que pone en práctica el feminismo de la igualdad. La pregunta que queda es por qué no se casó nunca ni tuvo hijos. ¿Intuyó que, de haberlo hecho, no habría podido actuar de la misma manera?

Laforet, Avia o Martín Gaite no buscaron ejercer una actividad profesional, aunque lo acabaron haciendo, incluso en ciertas fases de sus vidas, muy intensamente. Las dos primeras anticipan, de distintas maneras, cuestiones de hoy sobre la identidad y la diferencia entre mujeres y hombres. Carmen Laforet reflexiona sobre cómo ser mujer y escritora, sin que parezca conciliar fácilmente uno y otro aspecto de su personalidad. Amalia Avia, en cambio, parece haber podido compaginar sus roles familiares con una dedicación parcial al arte. Solo al final de su vida, al hacer balance, se pregunta si no hubo en ello una renuncia. En el discurso o en la realidad, ambas construyen una forma de ser artista diferente de la de los hombres. El retrato de Carmen Martín Gaite es el más incompleto. Parecen faltar piezas para reconstruir mínimamente su historia de vida, en la que, además, hay fases muy distintas, desde la incipiente o parcial dedicación a la literatura en su juventud hasta el trabajo continuo de escritora que desarrolla durante las dos últimas décadas de su vida.

Alejandra Val Cubero se refiere al frecuente reconocimiento póstumo de las artistas españolas, incluso en el caso de Mallo, al menos en su país. Sin embargo, a la vez se van conociendo cada vez más casos de artistas mujeres, en España y fuera de España, que alcanzaron notoriedad y éxito durante su vida, es decir, consiguieron hacer de su arte una profesión, pero que fueron después olvidadas por historiadores y cánones artísticos. Podrían mencionarse pintoras como Sofonisba Anguisola, olvidada durante siglos, o escultoras como La Roldana o Camille Claudel, solo recientemente recuperadas del olvido. Urge, por tanto, una doble recuperación de las artistas, tanto de las que alcanzaron en vida fama y reconocimiento, como de aquellas a las que solo póstumamente se les reconoce su arte.

\section{Referencias bibliográficas}

BeLL, Quentin (1972). Virginia Woolf: A biography. Londres: Harvest Books.

Bourdieu, Pierre (1988). La distinción: Criterios y bases sociales del gusto. Madrid: Taurus.

- (1991). El sentido práctico. Madrid: Taurus.

FraSER, Nancy y HONNETH, Axel (2006). ¿Redistribución y reconocimiento?: Un debate político-filosófico. Madrid: Morata.

FrIEDAN, Betty (1974). La mistica de la feminidad. Madrid: Júcar.

IZQUIERDO LÓPEZ, Natalia (2013). «Escritoras de la posguerra frente al espejo. Derrotas y conquistas de algunas antiheroinas». Papers, 98 (4), $\mathrm{xx}-\mathrm{xx}$

Nuevo Cal, Carlos e Ínsua López, Emilio (2011). Maruja Mallo: De Prometedora Pioneira a Artista Universal. A Coruña: Fundación Caixa Galicia.

Pateman, Carol (1989). The Disorder of Women. Cambridge: Polity Press. 
STUART Mill, John y TAYLOR Mill, Harriet (2001). Ensayos sobre la igualdad sexual. Madrid: Cátedra.

VAl Cubero, Sandra (2013). «La profesionalización de las mujeres artistas españolas. El caso de Maruja Mallo (1902-1995) y Amalia Avia (1926-2011)». Papers, 98 (4), $\mathrm{xx}-\mathrm{xx}$

VVAA (2008). Los lieder de Gustav y Alma Mahler. Madrid: Hiperión.

Wollstonecraft, M. (1977). Vindicación de los derechos de la mujer. Madrid: Debate. Woolf, V. (2008). Una habitación propia. Barcelona: Seix-Barral. 